\title{
Research on the Application of Flipped Classroom on English Language Skill Teaching
}

\author{
Hong Zhou \\ Changsha Medical University, Changsha, Hunan, 410219
}

Keywords: flipped classroom; English language; skill teaching

\begin{abstract}
Under the wave of education informatization reform in China, flipped classroom originated in the American education community is guided by constructivism theory and based on modern information technology. As an innovative teaching model, it is educating our country with its unique advantages, the attention and favor of the community. This paper is guided by the reform of educational informationization. It begins with the origin and definition analysis of flipped classroom and starts from the current status of college English teaching. It expounds the feasibility analysis and advantages of flipped classroom to guide college English teaching, and puts forward relevant countermeasures and suggestions. The classroom practice examples are given in order to provide reference for the implementation of college English flipped classroom practice in Chinese colleges and universities.
\end{abstract}

\section{Introduction}

College English teaching, as a public foundation course in China's higher education, is the forerunner and founder of the college curriculum reform. The quality of college English teaching and the effect of student learning all affect the teaching of other subjects more or less. Therefore, college English courses have become a new era of college students to learn professional knowledge, expand the international perspective and improve the competitiveness of employment The key lies. Although the reform of college English teaching in China has been implemented for many years, some colleges and universities still rely on teaching as the traditional teaching model. Teachers upload textbooks in class according to the syllabus, and students are often busy with club activities or part-time work. The issues, no time to review and consolidate the lessons learned, which to a certain extent affected the effectiveness of college English teaching. At present, the flipping classroom originated in the United States, as a new teaching idea and method for subverting traditional teaching methods, has increasingly become a focus of reform in the global education community. Although the flipping classroom has been widely promoted and implemented in the United States, and highly praised and widely recognized by the teachers and students in the United States, the research and application of flipping classrooms in China is still at the initial stage. Nowadays, the rapid development of China's information technology, the promotion and application of network technology, and the effective implementation of the Ministry of Education's plans have provided a wide range of platforms and good opportunities for the dissemination and application of overturned classrooms. It can be said that innovating the innovative teaching model built by the classroom is the product of education informatization, and it is also the "breaking innovation" of the traditional teaching model. Turning the classroom as an internationalized innovative teaching model has a unique advantage that cannot be matched by traditional teaching. The introduction of flipped classrooms and its application in Chinese college English teaching practice can effectively break through the predicament of the development of college English teaching and make it a good choice for Chinese college students. The English learning facility facilitates, in essence, the deepening of reforms in college English teaching, from the perspective of listening, speaking, reading, writing, and translation to practically improve the level of college English teaching in China and the comprehensive ability of college students to use English. 


\section{The Feasibility Analysis of Flipped Classroom and College English Teaching Practice}

At present, compared to the English teaching in the junior high schools, although the college English teaching is not bound by the pressure of further education, some local colleges and universities still use the non-English majors to pass the college English exams CET-4, TOEFL, IELTS, and postgraduate English exams. As the main teaching goal, the main line of exam-oriented education has been adopted and urgently needed to be reformed. As a language and culture study, English should pay more attention to the cultivation of communication skills such as English listening and speaking, and the improvement of listening and speaking skills is based on the students' solid knowledge of basic vocabulary, grammar, reading comprehension, and writing. And under the comfortable premise, these need to be completed in a good language environment. Because college English teaching is often limited by limited teaching time, fixed teaching venues, and limited content of teaching materials, it is difficult to create a good and perfect English language environment. Therefore, it is difficult to achieve non-English major students from listening, speaking, reading, writing, and translating. Training of orientation skills and comprehensive improvement. The teacher taught the students the knowledge of textbooks in class within 45 minutes. The students were busy focusing on taking notes and taking notes. They had little chance to speak and speak in English. Even if they had the opportunity to speak English, they were nervous, scared, shy, shy, etc. If they dare not open their mouths, teachers will not be able to give timely guidance on pronunciation correction, language listening and speaking. Some English classes even have stereotyped teaching content, tedious classroom design, and rigid teaching modes. Students will only learn and use it in college English classes. Over time, students will become tired, bored and boring. They will not be able to achieve communion and will seriously affect the effectiveness of college English teaching.

According to Eric Mazur's theory, in general, the process of learning mainly includes knowledge transfer and knowledge internalization. The traditional teaching model is that the teacher conducts knowledge transfer in the classroom first, and the students finish the knowledge internalization by completing the tasks reserved by the teachers under the class. Once the students encounter problems in the process of internalizing the knowledge, the teachers are not there. Failure to provide timely help affects the effectiveness of knowledge internalization. The essence of flipping the classroom implementation process is to reverse the two processes of "knowledge transfer" and "knowledge internalization" in the traditional teaching mode, and transfer the knowledge transfer process from the classroom to the classroom or home, and the process of knowledge internalization from under the classroom. Or to transfer from the family to the classroom, from the two dimensions of time and space to achieve a complete flip of the learning process, is a new paradigm of "first learn after teaching". In addition, the process of student internalization of knowledge is accompanied and participated by the teacher throughout the process, which helps to solve student's problems in a timely and effective manner. In the process of discussion and cooperation with classmates, students can truly digest and consolidate and integrate them. "Knowledge internalization" plays a key role in this learning process to maximize the effectiveness of teaching, so that both teaching effects and learning effects will produce a qualitative leap. This is precisely the biggest advantage of flipping the classroom compared to the traditional classroom. In the flipping classroom teaching mode, college English teachers should first concentrate on the difficult and difficult points of the teaching materials into 15-20 minutes of micro-video. The teacher does not appear in the video. There are only clear explanations and explanations for the knowledge points. This avoids the students being distracted by the teachers' different information in the dress and other classes when watching the video. Teachers can integrate animation, storytelling, interesting questions and other elements into the production of micro-video, so that students get rid of tedious textbook learning, is no longer limited by dull textbook content, entertaining, but also to stimulate students Interest in college English learning. Because the video is short and swift, it eliminates the disadvantages that traditional classrooms require 45 minutes of lectures to distract students. Students concentrate on pre-watching micro-videos in class or at home, and complete online exercises to self-check beginners. At the same time, according to their own digestion and absorption of new knowledge, 
they decide whether to play back, pause, or repeat the play. This is equivalent to the process of teachers transferring knowledge in the traditional classroom, which overcomes the one-way nature of traditional classroom knowledge transfer and saves knowledge transfer.

\section{Flipped Classroom to Guide the Specific Operation of College English Teaching Practice}

In the flipping classroom teaching mode, college English teachers must complete the transition from "teacher-centered" to "student-centered" in the entire process of college English teaching. Teachers must first adjust their mentality, change their concepts, and accept the new teacher-student relationship that is equal in the concept of teachers and students in terms of concepts, eliminate hierarchical concepts, and release them from the right to have almost absolute discourse. They are no longer the authoritative instructors of knowledge. It is an instructor who assists students to study independently and dispel doubts. As teachers, teachers need to understand each student's internal potential and intelligence, master the differences in their learning progress and differentiate their understanding, and how to provide differentiated "one-on-one" counseling for students in the classroom. In the time and space, it effectively solves each student's difficult confusion, promotes his personality development, and abandons the original stereotyped popular teaching. These changes all pose great challenges to teachers. Teachers need to improve their proficiency in business. At the same time, they have all-round excellent guidance capabilities (including integration of resources, judgment, professionalism, business ability, communication skills, collaboration skills, and communication skills.

With the increasing popularity of computers, the widespread use of the Internet, and the rapid development of cloud technologies, our lives have entered the era of big data. Information technology has quietly penetrated into all areas of life, and the education sector has not escaped this baptism. In order to successfully apply the flipping classroom in college English teaching practice, both teachers and students should effectively improve their IT literacy and computer application skills. First of all, the production of teaching videos puts higher requirements on teachers' information technology. Teachers can only master certain information technology and computer application skills, integrate information elements such as course difficulty points into short and elaborate videos, and design conformity tests. Practice can achieve the smooth and unobstructed knowledge transfer of micro video, and can track student's self-learning progress and knowledge mastery in real time. Similarly, students can only use mobile terminals such as computer terminals, tablet computers, or smart phones to effectively complete self-study before class and their pre-class exercises (ie, online self-tests) on the basis of a certain level of computer application. Find out where the crux of the problem is. Therefore, the level of information technology should not be an obstacle to the development of a new model of university-based English teaching. Both teachers and students should strengthen their own IT literacy and the level of computer applications. This is the basis and prerequisite for effectively carrying out interactive classroom exchanges. Specific effective protection.

The effectiveness of self-learning micro video lessons before class is directly affected by the implementation and effectiveness of the "knowledge internalization" process. Flipping the classroom makes the traditional teaching model, the teacher's one-way transfer of knowledge to students to students to watch micro video implementation of the reverse exploration of knowledge, which is a complete transformation of the process of knowledge transfer and a useful complement. This also puts forward higher requirements for students' autonomous learning ability and self-discipline. Before class, students became automatic adjusters of learning paces, that is, they chose to study time and space according to their own learning situations and master the progress and pace of learning content and learning volume. During the class, they are highly involved in the interaction with teachers and classmates, and continue to expand and create new knowledge with a certain breadth and depth during the discussion. The improvement of students' autonomous learning ability and the development of individualized learning benefits students throughout their lives. This is the fundamental way to truly improve the effectiveness of college English teaching, and it is also the only choice for realizing students' sublimation from school education to lifelong self-education. 


\section{Conclusion}

In view of the urgent need for the reform of college English teaching in China, the introduction and practice of flipping classrooms can, to a certain extent, make up for the defects of college English teaching, accurately grasp the objective laws of its development, and steadily break through its development bottlenecks, while also maximizing student development. The subjective initiative to improve students' learning efficiency and effectiveness has omni-directionally designed a set of successful programs that are in line with development and feasible for China's current college English teaching reform and development.

\section{References}

[1] Wang Yu, Cui Tingting, Wang Qinghua. Exploration of Integration of Information Technology and College English Curriculum [J]. China Electro-Technical Education, 2012, (2): 118-120.

[2] Zhang Jinlei, Wang Ying, Zhang Baohui. Research on Teaching Mode of Overturning Class [J]. Journal of Distance Education, 2012, (8): 46-51.

[3] Song Yanling, Meng Zhaopeng, Yan Yajuan. Exploring the Overturned Classroom from the Perspective of Cognitive Load--Analysis on Typical Models of Overturned Classroom [J]. Journal of Distance Education, 2014, (1): 105-112.

[4] Ma Mingshan, Qiao Dandan, Wang Xiangzheng. Evaluation and Enlightenment of Khan Academy Curriculum in Public View [J]. China Electro-Technical Education, 2014, (1): 93-98.

[5] Wu Zhongliang, Zhao Lei. A Preliminary Study of the Flip Classroom Teaching Mode Based on Web-based Learning Space [J]. China Electro-Technical Education, 2014, (4): 121-126. 